\title{
Produtividade e qualidade de raízes de batata-doce propagadas por diferentes tamanhos de miniestacas
}

Productivity and quality of sweet potato roots propagated by different sizes of mini cuttings

\author{
M. D. Nasser ${ }^{1 *}$, A. I. I. Cardoso 2 , A. B. Rós ${ }^{3}$, F. A. C. Mariano-Nasser ${ }^{2}$, L. F. \\ Colombari², J. A. Ramos ${ }^{2}$, K. A. Furlaneto ${ }^{2}$ \\ ${ }^{1}$ Pólo Regional Alta Paulista, Agência Paulista de Tecnologia dos Agronegócios, APTA, 17800-000, Adamantina- \\ SP, Brasil \\ ${ }^{2}$ Departamento de Horticultura, Universidade Estadual Paulista "Júlio de Mesquita Filho" (UNESP), 18610-034, \\ Botucatu-SP, Brasil \\ ${ }^{3}$ Pólo Regional Alta Sorocabana, Agência Paulista de Tecnologia dos Agronegócios, APTA, 19015-970, Presidente
} Prudente - SP, Brasil

*mdnasser@apta.sp.gov.br

(Recebido em 18 de dezembro de 2019; aceito em 01 de julho de 2020)

\begin{abstract}
Existem poucas pesquisas com propagação de batata-doce por miniestaquia. Objetivou-se com o presente trabalho avaliar a produtividade e a qualidade de batata-doce proveniente de diferentes tamanhos de miniestacas produzidas em bandeja plástica. As miniestacas de batata-doce da cv. Canadense foram produzidas em substrato comercial e acondicionadas em bandejas plásticas com 162 células. Foram estudados 9 tratamentos: "ramas semente" e miniestacas com 2 e 3 nós, retirados de diferentes posições das "ramas sementes". Desta forma, obteve-se miniestacas com 2 nós contendo $1^{\circ}$ e $2^{\circ}$ nós, $3^{\circ}$ e $4^{\circ}$ nós, $5^{\circ}$ e $6^{\circ}$ nós e $7^{\circ}$ e $8^{\circ}$ nós; e miniestacas com 3 nós contendo do $1^{\circ}$ ao $3^{\circ}$ nó, do $4^{\circ}$ ao $6^{\circ}$ nó, do $7^{\circ}$ ao $9^{\circ}$ nó e do $10^{\circ}$ ao $12^{\circ}$ nó. Adotou-se delineamento experimental em blocos ao acaso, com 7 repetições, sendo 7 mudas por repetição. Aos 48 dias após o plantio das miniestacas em viveiro, realizou-se transplante para o campo. Aos 146 dias de campo, as batatas-doces foram colhidas e foram quantificadas: produtividade comercial e total em $\mathrm{t} \mathrm{ha}^{-1}$, e taxa de sobrevivência em porcentagem. Raízes tuberosas foram separadas para avaliação das seguintes características químicas: açúcar redutor, sacarose, açúcar redutor total e amido. "Em geral, as miniestacas são indicadas para o cultivo, pois apresentam produtividade e qualidade viável para comercialização".

Palavras-chave: Ipomoea batatas L. (Lam.), produção de mudas, olericultura.
\end{abstract}

There is little research about sweet potato propagation by mini cuttings. The objective of this work was to evaluate the productivity and quality of sweet potato from different sizes of mini cuttings produced in plastic tray. Sweet potato cv. Canadense mini cuttings were produced on commercial substrate and packed in 162-cell trays. Nine treatments were studied: "seed branches" and segments of mini cuttings with 2 and 3 knots, taken from different positions of the "seed branches". In this way we obtained mini cuttings with 2 nodes from the $1^{\text {st }}$ and $2^{\text {nd }}$ node, $3^{\text {rd }}$ and $4^{\text {th }}$ node, $5^{\text {th }}$ and $6^{\text {th }}$ node and $7^{\text {th }}$ and $8^{\text {th }}$ node; and mini cuttings with 3 nodes from $1^{\text {st }}$ to $3^{\text {rd }}$ node, $4^{\text {th }}$ to $6^{\text {th }}$ node, $7^{\text {th }}$ to $9^{\text {th }}$ node and $10^{\text {th }}$ to $12^{\text {th }}$ node. A randomized complete block design was adopted with 7 replications, 7 seedlings per repetition. At 48 days after planting the mini cuttings in nursery, transplantation was performed to the field. At 146 days of field, sweet potatoes were harvested and quantified: commercial and total yield in t ha-1, and survival rate (percentage). Tuberous roots were separated to evaluate the following chemical characteristics: reducing sugar, sucrose, total reducing sugar and starch. In general, mini-cuttings are indicated for cultivation, as they present productivity and viable quality for commercialization".

Keywords: Ipomoea batatas L. (Lam.), seedling production, olericulture.

\section{INTRODUÇÃO}

A batata-doce (Ipomoea batatas L. (Lam.)) pertence à família Convolvulaceae, e no Brasil ocupa o quarto lugar no consumo de hortaliças [1]. Conforme relatado pelo IBGE (2019) [2], em 2017, o Estado de São Paulo foi o segundo maior produtor da raiz tuberosa, perdendo apenas para o RS, sendo a região de Presidente Prudente a segunda maior produtora do Estado de São Paulo. 
Esta planta herbácea, de raízes tuberosas e origem das regiões tropicais na América do Sul é cultivada como anual, mas considerada como planta perene [3]. Manejada adequadamente em solo e clima favoráveis, a produtividade varia entre 20 a $40 \mathrm{t} \mathrm{ha}^{-1}[1,3,4,5]$. As raízes apresentam elevados teores de carboidratos, retinol, ácido ascórbico, vitaminas do complexo B, além de minerais [6].

Tradicionalmente, as ramas maduras ou mais velhas são utilizadas no plantio da batata-doce por questões econômicas e facilidade na obtenção do material, porém pode favorecer a incidência de doenças e pragas no novo cultivo, além de baixo crescimento ao se comparar com as ramas novas $[1,3]$. Para implantar a batata-doce, utiliza-se a propagação vegetativa desse material, assim o uso de segmentos de ramas não enraizados pode resultar em estande final inadequado. Neste aspecto, torna-se necessário o replantio quando ocorrer menos de $85 \%$ de ramas brotadas [7].

$\mathrm{Na}$ produção de hortaliças é normal o uso de bandejas para produzir mudas propagadas por sementes. Este sistema geralmente é conduzido sob ambiente protegido e proporciona facilidade nos tratos culturais; e após o transplante, maior taxa de sobrevivência e uniformidade no campo $[8,9]$. No entanto, há culturas que são propagadas por meio de estacas e conduzidas em ambiente protegido. O comprimento das estacas é um fator importante para a produção de mudas, visto que o comprimento da estaca está relacionado a quantidade de substancias reservas e número de gemas. Trabalhos com tomateiro [10], hibisco [11] e carqueja [12] demonstram que há um comprimento mais adequado para a obtenção de mudas com maior enraizamento e viabilidade.

Assim, o conhecimento de que a produção de mudas de batata-doce a partir de miniestacas é viável [13] associado ao uso de ramas isentas de vírus, o que pode aumentar a produtividade em mais de 50\% [14], tem incentivado viveiristas a propagarem e comercializarem mudas de batatadoce com a finalidade de tornarem-se plantas matrizes fornecedoras de ramas. Porém, há poucos estudos avaliando a produtividade e qualidade das raízes tuberosas produzidas por plantas de batata-doce oriundas de miniestacas. Nesse sentido, objetivou-se neste trabalho avaliar a produtividade e a qualidade de batata-doce proveniente de diferentes tamanhos de miniestacas produzidas em bandeja plástica.

\section{MATERIAL E MÉTODOS}

Foram conduzidos dois experimentos no período de agosto de 2015 a fevereiro de 2016 na

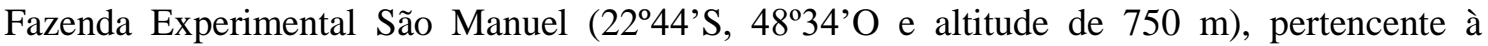
Faculdade de Ciências Agronômicas (FCA) da Universidade Estadual Paulista (UNESP), Campus de Botucatu, localizada no município de São Manuel-SP. Segundo a classificação de Köppen, o clima predominante do município de São Manuel é Cfa, ou seja, clima temperado quente (mesotérmico) úmido, com temperatura média do mês mais quente superior a $22^{\circ} \mathrm{C}$ [15]. A temperatura média anual é de $20,9^{\circ} \mathrm{C}$, e precipitação média anual de $1.395 \mathrm{~mm}$ [16].

As mudas de batata-doce foram produzidas em estufa agrícola não climatizada, tipo arco, com pé direito de $2,8 \mathrm{~m}$, largura de $7 \mathrm{~m}$, comprimento de $20 \mathrm{~m}$ e cobertura de polietileno transparente de $150 \mu \mathrm{m}$ de espessura, com tela anti-afídeos nas laterais.

As miniestacas de batata-doce da cv. Canadense, provenientes de plantas matrizes isentas de vírus, foram inseridas em substrato Carolina ${ }^{\circledR}$ e acondicionadas em bandejas de polipropileno rígido com 162 células. Na fase de viveiro foi realizado um experimento com 8 tratamentos, com segmentos de miniestacas com 2 e 3 nós, retirados de diferentes posições das ramas sementes. As ramas sementes foram coletadas sempre da porção jovem (ramas com até $60 \mathrm{~cm}$ ) de plantas matrizes produzidas em ambiente protegido, iniciando a contagem dos nós pela parte apical da haste. Considerou-se a contagem dos nós a partir da primeira folha com no mínimo $2 \mathrm{~cm}$. Desta forma, obtiveram-se miniestacas com 2 nós contendo I) $1^{\circ}$ e $2^{\circ}$ nós, II) $3^{\circ}$ e $4^{\circ}$ nós, III) $5^{\circ}$ e $6^{\circ}$ nós e IV) $7^{\circ}$ e $8^{\circ}$ nós; e mudas com 3 nós contendo V) $1^{\circ}$ ao $3^{\circ}$ nó, VI) $4^{\circ}$ ao $6^{\circ}$ nó, VII) $7^{\circ}$ ao $9^{\circ}$ nó e VII) $10^{\circ}$ ao $12^{\circ}$ nó. O delineamento experimental foi em blocos ao acaso, com 7 repetições, sendo 7 mudas úteis por repetição.

Retiraram-se as folhas das miniestacas com tesoura de poda e foi inserida uma gema (basal) no substrato, ficando uma ou duas gemas acima do substrato, de acordo com o número de gemas da estaca. As bandejas forma mantidas a 1,0 $\mathrm{m}$ do chão, sobre bancada feita de arame, favorecendo a poda das raízes por desidratação. Aos 48 dias após plantio das miniestacas em viveiro, realizou- 
se transplante para o campo, em solo classificado como Latossolo Vermelho Distrófico Típico [17] e os resultados da análise química, na profundidade de $0-20 \mathrm{~cm}$, foram: $\mathrm{pH}\left(\mathrm{CaCl}_{2}\right)=5,8$; M.O. $=16 \mathrm{~g} \mathrm{dm}^{-3} ;$ Presina $=101 \mathrm{mg} \mathrm{dm}^{-3} ; \mathrm{H}+\mathrm{Al}=17 \mathrm{mmol}_{\mathrm{c}} \mathrm{dm}^{-3} ; \mathrm{K}=3,0 \mathrm{mmol}_{\mathrm{c}} \mathrm{dm}^{-3} ; \mathrm{Ca}=$ $35 \mathrm{mmol}_{\mathrm{c}} \mathrm{dm}^{-3} ; \mathrm{Mg}=10 \mathrm{mmol}_{\mathrm{c}} \mathrm{dm}^{-3} ; \mathrm{SB}=48 \mathrm{mmol}_{\mathrm{c}} \mathrm{dm}^{-3} ; \mathrm{CTC}=65 \mathrm{mmolc} \mathrm{dm}^{-3} ; \mathrm{e} \mathrm{V} \%=74$.

Em campo, adotou-se delineamento experimental em blocos ao acaso, sendo estudados 9 tratamentos. Os tratamentos foram compostos por 8 tratamentos com miniestacas (tratamentos I, II, III, IV, V, VI, VII e VIII, descritos no trabalho em viveiro) e 1 tratamento (IX) com "rama semente", semelhante ao utilizado pelo produtor, com aproximadamente $30 \mathrm{~cm}$ de comprimento. Foram realizadas 6 repetições, sendo uma linha de plantio por parcela, 6 plantas por parcela, e avaliadas as 4 plantas centrais. Os tratos culturais foram iguais em todos os tratamentos, utilizouse irrigação por aspersão, evitando o ponto de murcha permanente das plantas; e aos 28 dias após o transplante realizou-se adubação de cobertura com $35 \mathrm{Kg}$ de N e $35 \mathrm{Kg}_{\text {de }} \mathrm{K}_{2} \mathrm{O}$ ha ${ }^{-1}$ através do fertilizante formulado 20.00.20. O espaçamento de plantio adotado foi $0,80 \mathrm{~m}$ x $0,40 \mathrm{~m}(31.250$ plantas ha $\left.^{-1}\right)$. A implantação e os tratos culturais até a colheita seguiram as recomendações técnicas conforme Peressin e Feltran (2014) [1], Filgueira (2008) [3] e Silva et al. (2008) [18].

$\mathrm{Na}$ fase de viveiro, aos 48 dias após o plantio nas bandejas, foram avaliados enraizamento (ERZ), massa da matéria seca de raiz (MSR), massa da matéria seca de miniestaca (MSME) isenta de folhas e brotações emitidas durante desenvolvimento em viveiro, massa da matéria seca de folhas e brotações (MSFB), número de folhas (NF) e número de raízes primárias (NR1 $1^{\mathrm{a}}$ ), que são aquelas que saíram diretamente da miniestaca. As massas de matéria seca foram obtidas a partir da massa fresca dos materiais submetida à secagem com secagem em estufa a $65^{\circ} \mathrm{C}$, com circulação forçada de ar, até atingir massa constante. Aos 146 dias de campo, as batatas-doces foram colhidas e foram quantificadas a taxa de sobrevivência em porcentagem, a produtividade comercial e total em $\mathrm{t} \mathrm{ha}^{-1}$, e o número de raízes e a massa média de raiz por planta. A produtividade foi calculada pela massa fresca de raízes obtidas por planta multiplicada pelo número de plantas por hectare. Foram consideradas comerciais, raízes com massa de 80 a $500 \mathrm{~g}$, sem defeitos aparentes e formato adequado para comercialização.

Após a colheita, as batatas-doce foram lavadas e 3 raízes comerciais por parcela foram separadas para avaliação das seguintes características químicas: açúcar redutor, sacarose, açúcar redutor total e amido. Foi utilizada metodologia de Somogyi e adaptada por Nelson (1944) [19], sendo os resultados expressos em porcentagem.

Foi realizada análise de variância para todos os dados, e ao verificar significância pelo Teste F, compararam-se as médias dos tratamentos pelo Teste de Tukey ao nível de significância de 5\%. Utilizou-se o programa estatístico SISVAR [20].

\section{RESULTADOS E DISCUSSÃO}

No experimento realizado no viveiro, não houve diferença significativa para a variável enraizamento das miniestacas (Tabela 1). Todos os tratamentos apresentaram elevada percentagem de enraizamento, com valor médio de 92,88\%. A elevada percentagem de enraizamento das miniestacas era esperada, visto que Rós e Narita (2011c) [21] obtiveram 99\% de brotação de miniestacas de batata-doce da mesma variedade estudada no presente estudo e Rós et al. (2011b) [13] relataram elevado enraizamento de miniestacas de 25 clones da batata-doce. Portanto, as pesquisas já realizadas com miniestacas de batata-doce indicam que estas apresentam facilidade em enraizar mesmo sem a utilização de reguladores que promovem o enraizamento.

Quanto à massa seca de raízes de mudas de batata-doce foi verificado que a utilização de estacas com 3 nós, do $7^{\circ}$ ao $9^{\circ}$ nó, resultou em maior valor que as estacas com 2 nós (exceto as estacas com 2 nós, $7^{\circ}$ e $8^{\circ}$ nós) (Tabela 1 ). Esse resultado deve-se, provavelmente, ao fato de as estacas com 3 nós, do $7^{\circ}$ ao $9^{\circ}$, serem maiores e, consequentemente, possuírem maior quantidade de substâncias de reserva e por possuírem porções menos jovens que aquelas que apresentaram apenas 2 nós, sendo, nestas utilizadas até no máximo o $6^{\circ}$ nó $\left(1^{\circ}\right.$ e $2^{\circ}$ nós, $3^{\circ}$ e $4^{\circ}$ nós, e $5^{\circ}$ e $6^{\circ}$ nós).

Na variável massa seca de folhas e brotações (Tabela 1), nota-se valores médios maiores para estacas com 3 nós, porém não diferem estatisticamente das estacas com 2 nós. Em trabalhos de Pizzatto et al. (2011) [11] e Gomes e Krinski (2016) [22], também foi verificado que estacas 
maiores de hibisco e malvavisco, respectivamente, resultaram em mudas com maior número de brotos vegetativos e de raízes.

A massa seca de miniestaca também foi influenciada pelo número de nós e posição da miniestaca na rama. As estacas com 3 nós e porção do $10^{\circ}$ ao 12 nó apresentaram massa seca superior aos outros tratamentos, com exceção das estacas com 3 nós e porção do $7^{\circ}$ ao $9^{\circ}$ nó que apresentaram valor estatisticamente semelhante. Esse resultado deve-se ao fato de aquelas miniestacas apresentarem um maior comprimento que as estacas com 2 nós e terem sido retiradas da porção menos jovem estudada.

Tabela 1- Valores médios de enraizamento, matéria seca de raiz (MSR), matéria seca de miniestaca (MSME), matéria seca de folhas e brotações (MSFB), número de folhas (NF) e número de raízes primárias $\left(N R 1^{a}\right)$ de miniestacas com 2 ou 3 nós e oriundas de diferentes posições da estaca (com nós contados a partir da porção apical da rama) da batata-doce cv. Canadense aos 48 dias após plantio em bandejas plásticas. São Manuel, SP. 2015.

\begin{tabular}{|c|c|c|c|}
\hline $\begin{array}{l}\text { Tratamentos } \\
\text { (miniestacas) }\end{array}$ & $\begin{array}{c}\text { Enraizamento } \\
(\%)\end{array}$ & $\begin{array}{c}\text { MSR } \\
\left(\mathrm{g} \mathrm{muda}^{-1}\right)\end{array}$ & $\begin{array}{c}\text { MSME } \\
\left(\text { g muda }^{-1}\right)\end{array}$ \\
\hline 2 nós $-1^{\circ}$ e $2^{\circ}$ nós & $87,76 \mathrm{a}$ & $0,11 \mathrm{~b}$ & $0,09 \mathrm{~d}$ \\
\hline 2 nós $-3^{\circ}$ e $4^{\circ}$ nós & $85,71 \mathrm{a}$ & $0,11 \mathrm{~b}$ & $0,10 \mathrm{~d}$ \\
\hline 2 nós $-5^{\circ}$ e $6^{\circ}$ nós & $91,84 \mathrm{a}$ & $0,11 \mathrm{~b}$ & $0,12 \mathrm{~cd}$ \\
\hline 2 nós $-7^{\circ}$ e $8^{\circ}$ nós & $91,84 \mathrm{a}$ & $0,13 a b$ & $0,18 \mathrm{bc}$ \\
\hline 3 nós $-1^{\circ}$ ao $3^{\circ}$ nó & $100,00 \mathrm{a}$ & $0,16 a b$ & $0,17 \mathrm{~cd}$ \\
\hline 3 nós $-4^{\circ}$ ao $6^{\circ}$ nó & $93,88 \mathrm{a}$ & $0,18 \mathrm{ab}$ & $0,18 b c$ \\
\hline 3 nós $-7^{\circ}$ ao $9^{\circ}$ nó & $93,88 \mathrm{a}$ & $0,18 \mathrm{a}$ & $0,25 a b$ \\
\hline 3 nós $-10^{\circ}$ ao $12^{\circ}$ nó & $93,88 \mathrm{a}$ & $0,16 a b$ & $0,26 \mathrm{a}$ \\
\hline Média geral & 92,35 & 0,14 & 0,17 \\
\hline F & $1,17^{\mathrm{ns}}$ & $3,87 * *$ & $14,05 * *$ \\
\hline C. V. $(\%)$ & 14,79 & 29,42 & 26,60 \\
\hline $\begin{array}{l}\text { Tratamentos } \\
\text { (miniestacas) }\end{array}$ & $\begin{array}{c}\text { MSFB } \\
\left(\mathrm{g} \mathrm{muda}^{-1}\right)\end{array}$ & $\begin{array}{c}\text { NF } \\
\left(\text { unid. } \text { muda }^{-1} \text { ) }\right.\end{array}$ & $\begin{array}{c}\text { NR1 }^{\mathrm{a}} \\
{\text { (unid. } \text { muda }^{-1} \text { ) }}^{\text {(n) }}\end{array}$ \\
\hline 2 nós $-1^{\circ}$ e $2^{\circ}$ nós & $0,16 \mathrm{~b}$ & $4,81 \mathrm{~b}$ & $6,36 \mathrm{bcd}$ \\
\hline 2 nós $-3^{\circ}$ e $4^{\circ}$ nós & $0,19 \mathrm{~b}$ & $5,41 \mathrm{ab}$ & $6,09 \mathrm{~cd}$ \\
\hline 2 nós $-5^{\circ}$ e $6^{\circ}$ nós & $0,19 \mathrm{~b}$ & $5,04 \mathrm{~b}$ & $6,00 \mathrm{~cd}$ \\
\hline 2 nós $-7^{\circ}$ e $8^{\circ}$ nós & $0,22 a b$ & $6,06 \mathrm{ab}$ & $5,72 \mathrm{~d}$ \\
\hline 3 nós $-1^{\circ}$ ao $3^{\circ}$ nó & $0,22 a b$ & $5,02 \mathrm{~b}$ & $7,83 \mathrm{abc}$ \\
\hline 3 nós $-4^{\circ}$ ao $6^{\circ}$ nó & $0,20 \mathrm{~b}$ & $5,61 \mathrm{ab}$ & 7,08 abcd \\
\hline 3 nós $-7^{\circ}$ ao $9^{\circ}$ nó & $0,29 \mathrm{a}$ & $6,78 \mathrm{a}$ & $8,22 \mathrm{ab}$ \\
\hline 3 nós $-10^{\circ}$ ao $12^{\circ}$ nó & $0,25 \mathrm{ab}$ & $6,55 \mathrm{a}$ & $8,78 \mathrm{a}$ \\
\hline Média geral & 0,21 & 5,66 & 7,01 \\
\hline $\mathbf{F}$ & $3,82 * *$ & $5,24 * *$ & $6,24 * *$ \\
\hline C. V. (\%) & 24,42 & 15,00 & 17,31 \\
\hline
\end{tabular}

** Médias seguidas de mesma letra na coluna não diferem estatisticamente entre si pelo teste de Tukey (p $\leq 0,05)$. ns: não significativo.

Quanto ao número de folhas, as estacas com 3 nós, das porções do $7^{\circ}$ ao $9^{\circ}$ e do $10^{\circ}$ ao $12^{\circ}$ nó apresentaram maiores valores que estacas com 2 nós, das porções $1^{\circ}$ e $2^{\circ}$, e $5^{\circ}$ e $6^{\circ}$ nós e estacas com 3 nós, de $1^{\circ}$ ao $3^{\circ}$ nó. Em trabalho de Ehlert et al. (2004) [23] com estacas apicais e medianas de alfavaca cravo, também foi verificado que estacas apicais, em geral, resultam na produção de mudas com menor número de folhas. No entanto, Rós et al. (2018) [24] verificaram que estacas de batata-doce oriundas da porção apical e da porção de 22 a $30 \mathrm{~cm}$ não apresentaram diferença no valor do número de folhas.

Estacas com 3 nós, da porção $10^{\circ}$ ao $12^{\circ}$ nó, apresentaram maior número de raízes que estacas com 2 nós, independente da porção, ou seja, aquelas por possuírem mais substâncias de reserva e serem menos jovens produziram melhor resultado para essa característica. Ressalta-se que as estacas com 3 nós, da porção $10^{\circ}$ ao $12^{\circ}$ nó, não diferiram das demais estacas com 3 nós. Em 
trabalho de Rós et al. (2018) [24], as estacas apicais de batata-doce e de segmento mais velho, com mesmo tamanho, não apresentaram diferença para o número de raízes. Em trabalhos de Pizzatto et al. (2011) [11] e Gomes e Krinski (2016) [22], também foi verificado que estacas maiores de hibisco e malvavisco, respectivamente, resultaram em mudas com maior número de raízes. Nesse aspecto, supondo um possível veranico ou problema de irrigação no início do cultivo no campo, pode-se considerar que mudas de batata-doce produzidas por miniestaquia com 3 nós poderiam suportar o déficit hídrico por um período maior quando comparadas a mudas oriundas de miniestacas com 2 nós.

Quanto ao experimento realizado no campo, os tratamentos não diferiram quanto à taxa de sobrevivência, apresentando valor médio de 97,25\% (Tabela 2). A alta percentagem de sobrevivência a campo de miniestacas enraizadas de batata-doce já foi comprovada por Rós et al. (2011a) [5], que verificaram taxa média de sobrevivência a campo de 25 clones superior a 98\%, ou seja, valor semelhante ao desta pesquisa. Apesar da pequena reserva presente nas miniestacas, comparativamente as "ramas sementes", estas permaneceram em viveiro durante o enraizamento e brotação e as mudas foram a campo já enraizadas e com as raízes protegidas por um torrão.

A utilização de "ramas sementes", forma convencional de cultivo, promoveu a maior produtividade total de raízes tuberosas em relação ao uso de plantas oriundas de estacas com 2 ou 3 nós (Tabela 2). Ressalta-se que as raízes tuberosas de batata-doce se originam das gemas das estacas, ou seja, a produção por unidade de planta está relacionada ao número de gemas da "rama semente" enterradas [25]. Conforme Azevedo et al. (2000) [26], o maior número de gemas enterradas por rama, proporciona maior número de raízes tuberosas de batata-doce, mas com menor massa individual. $\mathrm{O}$ fato das miniestacas possuírem apenas uma gema enterrada pode justificar a menor produtividade total de raízes, e essa diferença de produção poderia ser diminuída com maior número de plantas oriundas de miniestacas por unidade de área.

Em relação à produtividade comercial, apenas dois tratamentos (estacas com 2 nós, $3^{\circ}$ e $4^{\circ}$ nós, e estacas com 3 nós, $10^{\circ}$ ao $12^{\circ}$ nó) apresentaram produtividade inferior as "ramas sementes" (Tabela 2). Esse resultado demonstra que as plantas oriundas de miniestacas apresentam maior porcentagem de raízes comerciais (produtividade comercial) em relação ao total de raízes produzidas (produtividade total) que plantas oriundas de "ramas sementes".

Esses resultados diferem do trabalho de Rós et al. (2011a) [5], onde as produtividades total e comercial não diferiram estatisticamente entre as miniestacas com 2 nós e "ramas sementes" com $30 \mathrm{~cm}$. Segundo Islam et al. (2006) [27] e He et al. (2000) [28], miniestacas podem apresentar maior produtividade de raízes tuberosas que "ramas sementes" oriundas de lavouras comerciais. E analisando o número de raízes por planta (NR) e a massa média de raízes por planta (MMedR), nota-se estatisticamente que as mudas de miniestacas não apresentaram diferenças com relação à "rama semente", com exceção das miniestacas com 3 nós, $10^{\circ}$ ao $12^{\circ}$ nó que proporcionaram no campo plantas com menos raízes, e também menor produtividade. Neste caso, torna-se interessante avaliar se miniestacas retiradas de porções mais velhas das ramas matrizes podem resultar em menores produtividades de raízes tuberosas.

A composição química das raízes tuberosas, em termos de açúcar redutor e amido apresentaram variação entre os tratamentos (Tabela 2). O uso de "ramas sementes" resultou em raízes com menor porcentagem de açúcar redutor que os tratamentos com estacas com 2 nós, $3^{\circ} \mathrm{e}$ $4^{\circ}$ nós; 3 nós, $1^{\circ}$ ao $3^{\circ}$ nó; e 3 nós, $10^{\circ}$ ao $12^{\circ}$ nó. Porém, em relação ao teor de amido, as batatasdoces oriundas de "ramas sementes" proporcionaram valores superiores quando comparadas as batatas-doces provenientes de mudas propagadas por miniestaquia, com exceção do tratamento de 2 nós, $5^{\circ}$ e $6^{\circ}$ nós. Com os resultados expostos na Tabela 2, associado à realização da colheita 146 dias após o plantio, pode ser que batatas-doces produzidas por miniestaquia necessitem de maior tempo de cultivo no campo para alcançar valores de produtividade total e carboidratos semelhantes aos encontrados em "ramas sementes" que já são utilizados comercialmente. Wang (1982) [29] relatou que o teor de amido é altamente correlacionado ao teor de matéria seca. Mesmo que o maior tempo de cultivo possa elevar o custo de produção da batata-doce propagada por miniestaquia, Echer et al. (2009) [30] analisaram distribuição da matéria seca entre órgãos da batata-doce cv. Canadense e observaram aumento de matéria seca na raiz tuberosa durante todo ciclo até a colheita realizada aos 145 dias após o plantio. 
Tabela 2- Valores médios de taxa de sobrevivência das plantas (TXSOB), produtividades total (PTOTAL) e comercial (PCOM) de raízes tuberosas, número de raízes por planta (NR), massa média de raiz por planta (MMedR), açúcar redutor (AR), sacarose (SAC), açúcar total (AT) e amido (AM) de raízes tuberosas de plantas de batata-doce oriundas de miniestacas com 2 ou 3 nós e diferentes posições da estaca ou oriundas de "rama semente” da cv. Canadense aos 146 dias após o transplante a campo. São Manuel, SP. 2016.

\begin{tabular}{|c|c|c|c|c|c|}
\hline Tratamentos & $\begin{array}{c}\text { TXSOB } \\
(\%)\end{array}$ & $\begin{array}{c}\text { PTOTAL } \\
\left(\text { t ha }^{-1}\right)\end{array}$ & $\begin{array}{l}\text { PCOM } \\
\left(t_{\text {ha }^{-1}}\right)\end{array}$ & $\begin{array}{c}\text { NR } \\
\text { (unid. } \text { planta }^{-1} \text { ) }\end{array}$ & $\begin{array}{c}\text { MMedR } \\
\left(\text { g planta }^{-1}\right)\end{array}$ \\
\hline $\begin{array}{c}\text { Miniestaca com } 2 \text { nós - } \\
1^{\circ} \text { e } 2^{\circ} \text { nós }\end{array}$ & $100,00 \mathrm{a}$ & $21,16 \mathrm{~b}$ & $9,85 \mathrm{ab}$ & $3,08 \mathrm{ab}$ & $304,11 \mathrm{a}$ \\
\hline $\begin{array}{c}\text { Miniestaca com } 2 \text { nós - } \\
3^{\circ} \text { e } 4^{\circ} \text { nós }\end{array}$ & $100,00 \mathrm{a}$ & $16,05 \mathrm{~b}$ & $8,18 \mathrm{~b}$ & $3,04 \mathrm{ab}$ & $286,14 \mathrm{a}$ \\
\hline $\begin{array}{c}\text { Miniestaca com } 2 \text { nós - } \\
5^{\circ} \text { e } 6^{\circ} \text { nós }\end{array}$ & $75,00 \mathrm{a}$ & $30,73 \mathrm{~b}$ & $\begin{array}{c}11,80 \\
\mathrm{ab}\end{array}$ & $2,92 \mathrm{ab}$ & $359,69 \mathrm{a}$ \\
\hline $\begin{array}{c}\text { Miniestaca com } 2 \text { nós - } \\
7^{\circ} \text { e } 8^{\circ} \text { nós }\end{array}$ & $75,00 \mathrm{a}$ & $26,70 \mathrm{~b}$ & $\begin{array}{c}10,62 \\
\mathrm{ab}\end{array}$ & $3,29 \mathrm{ab}$ & $332,27 \mathrm{a}$ \\
\hline $\begin{array}{c}\text { Miniestaca com } 3 \text { nós - } \\
1^{\circ} \text { ao } 3^{\circ} \text { nó }\end{array}$ & $100,00 \mathrm{a}$ & $19,62 \mathrm{~b}$ & $\begin{array}{c}14,29 \\
\mathrm{ab}\end{array}$ & $3,67 \mathrm{ab}$ & $198,36 \mathrm{a}$ \\
\hline $\begin{array}{c}\text { Miniestaca com } 3 \text { nós - } \\
4^{\circ} \text { ao } 6^{\circ} \text { nó }\end{array}$ & $87,50 \mathrm{a}$ & $21,64 \mathrm{~b}$ & $9,93 \mathrm{ab}$ & $3,50 \mathrm{ab}$ & $269,57 \mathrm{a}$ \\
\hline $\begin{array}{c}\text { Miniestaca com } 3 \text { nós - } \\
7^{\circ} \text { ao } 9^{\circ} \text { nó }\end{array}$ & $100,00 \mathrm{a}$ & $21,30 \mathrm{~b}$ & $\begin{array}{c}11,48 \\
\mathrm{ab}\end{array}$ & $3,33 \mathrm{ab}$ & $236,47 \mathrm{a}$ \\
\hline $\begin{array}{c}\text { Miniestaca com } 3 \text { nós - } \\
10^{\circ} \text { ao } 12^{\circ} \text { nó }\end{array}$ & $75,00 \mathrm{a}$ & $22,02 \mathrm{~b}$ & $6,88 \mathrm{~b}$ & $2,43 \mathrm{~b}$ & $333,82 \mathrm{a}$ \\
\hline "Rama semente" & $100,00 \mathrm{a}$ & $52,30 \mathrm{a}$ & $20,31 \mathrm{a}$ & $5,33 \mathrm{a}$ & $396,86 \mathrm{a}$ \\
\hline Média geral & 97,25 & 25,72 & 11,48 & 3,40 & 301,92 \\
\hline $\mathbf{F}$ & $2,00^{\mathrm{ns}}$ & $7,03 * *$ & $2,57 *$ & $2,12^{*}$ & $1,21^{\mathrm{ns}}$ \\
\hline C. V. $(\%)$ & 3,94 & 38,80 & 52,34 & 40,04 & 45,61 \\
\hline Tratamentos & $\operatorname{AR}(\%)$ & \multicolumn{2}{|c|}{$\operatorname{SAC}(\%)$} & $\mathrm{AT}(\%)$ & $\mathrm{AM}(\%)$ \\
\hline $\begin{array}{c}\text { Miniestaca com } 2 \text { nós - } \\
1^{\circ} \text { e } 2^{\circ} \text { nós }\end{array}$ & $0,70 \mathrm{bc}$ & \multicolumn{2}{|c|}{$1,80 \mathrm{a}$} & $2,59 \mathrm{a}$ & $12,64 \mathrm{bc}$ \\
\hline $\begin{array}{c}\text { Miniestaca com } 2 \text { nós - } \\
3^{\circ} \text { e } 4^{\circ} \text { nós }\end{array}$ & $0,87 \mathrm{ab}$ & \multicolumn{2}{|c|}{$1,61 \mathrm{a}$} & $2,57 \mathrm{a}$ & $11,28 \mathrm{c}$ \\
\hline $\begin{array}{c}\text { Miniestaca com } 2 \text { nós - } \\
5^{\circ} \text { e } 6^{\circ} \text { nós }\end{array}$ & $0,73 \mathrm{abc}$ & \multicolumn{2}{|c|}{$1,64 \mathrm{a}$} & $2,45 \mathrm{a}$ & $14,10 \mathrm{ab}$ \\
\hline $\begin{array}{c}\text { Miniestaca com } 2 \text { nós - } \\
7^{\circ} \text { e } 8^{\circ} \text { nós }\end{array}$ & $0,78 \mathrm{abc}$ & \multicolumn{2}{|c|}{$1,63 \mathrm{a}$} & $2,49 \mathrm{a}$ & $13,43 \mathrm{bc}$ \\
\hline $\begin{array}{c}\text { Miniestaca com } 3 \text { nós - } \\
1^{\circ} \text { ao } 3^{\circ} \text { nó }\end{array}$ & $0,98 \mathrm{a}$ & \multicolumn{2}{|c|}{$1,73 \mathrm{a}$} & $2,80 \mathrm{a}$ & $13,40 \mathrm{bc}$ \\
\hline $\begin{array}{c}\text { Miniestaca com } 3 \text { nós - } \\
4^{\circ} \text { ao } 6^{\circ} \text { nó }\end{array}$ & $0,76 \mathrm{abc}$ & \multicolumn{2}{|c|}{$1,77 \mathrm{a}$} & $2,62 \mathrm{a}$ & $11,89 \mathrm{bc}$ \\
\hline $\begin{array}{c}\text { Miniestaca com } 3 \text { nós - } \\
7^{\circ} \text { ao } 9^{\circ} \text { nó }\end{array}$ & $0,76 \mathrm{abc}$ & \multicolumn{2}{|c|}{$1,81 \mathrm{a}$} & $2,67 \mathrm{a}$ & $12,12 \mathrm{bc}$ \\
\hline $\begin{array}{c}\text { Miniestaca com } 3 \text { nós - } \\
10^{\circ} \text { ao } 12^{\circ} \text { nó }\end{array}$ & $0,86 \mathrm{ab}$ & \multicolumn{2}{|c|}{$1,60 \mathrm{a}$} & $2,54 \mathrm{a}$ & $12,76 \mathrm{bc}$ \\
\hline "Rama semente" & $0,57 \mathrm{c}$ & \multicolumn{2}{|c|}{$1,77 \mathrm{a}$} & $2,43 \mathrm{a}$ & $16,24 \mathrm{a}$ \\
\hline Média geral & 0,78 & \multicolumn{2}{|c|}{1,71} & 2,57 & 13,10 \\
\hline $\mathbf{F}$ & $4,21 * *$ & \multirow{2}{*}{\multicolumn{2}{|c|}{$0,96 \mathrm{~ns}$}} & $1,59 \mathrm{~ns}$ & $6,99 * *$ \\
\hline C. V. $(\%)$ & 19,27 & & & 9,32 & 11,18 \\
\hline
\end{tabular}

* Médias seguidas de mesma letra na coluna não diferem estatisticamente entre si pelo teste de Tukey (p $\leq$ 0,05). ns: não significativo.

As demais propriedades, sacarose e açúcar total não diferiram entre os tratamentos. Pela média geral, nota-se que a porcentagem de sacarose de $1,71 \%$ foi praticamente o dobro do valor do açúcar redutor $(0,78 \%)$. Quanto ao conteúdo médio de amido em todos os tratamentos $(13,10 \%)$ 
foi próximo ao relatado por outros trabalhos que encontraram valores variando de $11,02 \%$ a $18,3 \%$ [31, 32, 33], mas foi superior ao encontrado por Corrêa et al. (2016) [34] que relataram valor médio de 6,14\% para cultivar Canadense e aos de Nóbrega et al. (2019) [35] que analisaram 10 acessos de batata-doce com média de $8,97 \%$ de amido na polpa.

\section{CONCLUSÃO}

Em geral, as miniestacas são indicadas para o cultivo, pois apresentam produtividade e qualidade viável para comercialização.

\section{REFERÊNCIAS BIBLIOGRÁFICAS}

1. Peressin VA, Feltran JC. Batata-doce: Ipomoea batatas (L.) Lam. In: Aguiar ATE, Gonçalves C, Paterniani MEAGZ, Tucci MLS, Castro CEF, editors. Instruções agrícolas para as principais culturas econômicas. 7. ed. rev. e atual. Campinas: Instituto Agronômico, 2014. (Boletim IAC, $\mathrm{n}^{\mathrm{o}}$ 200). p. 5961. Available from: <file:///C:/Users/user10/Downloads/boletim200_iac.pdf>.

2. Instituto Brasileiro de Geografia e Estatística - IBGE. Sistema IBGE de Recuperação Automática. 2019. Disponível em: https://sidra.ibge.gov.br/tabela/1612\#resultado.

3. Filgueira FAR. Convolvuláceas: batata-doce, a batata de clima quente. In:_. Novo manual de olericultura: agrotecnologia moderna na produção e comercialização de hortaliças. 3. ed. rev. e ampl. Viçosa, MG: Ed. UFV, 2008. p. 371-377.

4. Empresa Brasileira de Pesquisa Agropecuária - EMBRAPA. Cultivo da batata-doce (Ipomoea batatas (L.) Lam). Brasília: Ministério da Agricultura, Abastecimento e Reforma Agrária, 1995. 10 p. (Instruções técnicas 7).

5. Rós AB, Frias AG, Araújo HS, Santos HS. Produtividade de plantas de batata-doce oriundas de diferentes materiais de plantio. Hortic Bras. 2011(a);29(2):2719-2723.

6. Azevedo AM, Andrade Júnior VC, Fernandes JSC, Pedrosa CE, Oliveira CM. Desempenho agronômico e parâmetros genéticos em genótipos de batata-doce. Hortic Bras. 2015 Jan;33(1):84-90, doi: $10.1590 / \mathrm{S} 0102-053620150000100014$

7. Brune ES, Silva JBC, Franco IM. Definição de contentores para o enraizamento de estacas de batatadoce. Anais do $46^{\circ}$ Congresso Brasileiro de Olericultura; 2006; Goiânia, GO. Sociedade Brasileira de Horticultura; 2006. em:<http://www.abhorticultura.com.br/biblioteca/arquivos/Download/Biblioteca/46_0318.pdf>.

8. Reghin MY, Otto RF, Olinik JR, Jacoby CFS. Viabilidade do sistema de produção de mudas em bandejas em três cultivares de cebola. Ciênc Agrotec. 2007 Jul-Ago;31(4):1075-1084, doi: 10.1590/S1413-70542007000400020

9. Costa E, Durante LGY, Nagel PL, Ferreira CR, dos Santos A. Qualidade de mudas de berinjela submetida a diferentes métodos de produção. Rev Ciênc Agron. 2011 Out-Dez; 42(4):1017-1025, doi: 10.1590/S1806-66902011000400026

10. Souza LV, Gentil DFO. Estaquia da cultivar de tomateiro Yoshimatsu. Hortic Bras. 2013 Jan-Mar; 31(1):166-170, doi: 10.1590/S0102-05362013000100027

11. Pizzatto M, Wagner Júnior A, Luckmann D, Pirola K, Cassol DA, Mazaro SM. Influência do uso de AIB, época de coleta e tamanho de estaca na propagação vegetativa de hibisco por estaquia. Rev Ceres. 2011;58(4):487-492, doi: 10.1590/S0034-737X2011000400013

12. Bona CM, Biasi LA, Zanette F, Nakashima T. Propagação de três espécies de carqueja com estacas de diferentes tamanhos. Semina Ciênc Agr. 2005 Jan-Fev;25(3):179-84, doi: 10.1590/S010384782005000100037

13. Rós AB, Montes SMNM, Narita N, Tavares Filho J. Technical viability of the production of sweet potato plantlets in trays. Semina Ciênc Agr. 2011(b);32(4):1423-142, doi: 10.5433/16790359.2011v32n4p1423

14. Rós AB, Hirata ACS, Santos HS. Avaliação da produtividade de plantas de batata-doce oriundas de matrizes livres de vírus. Rev Bras Ciênc Agr. 2012;7(3):434-439, doi: 10.5039/agraria.v7i3a1716

15. Cunha AR, Martins D. Classificação climática para os municípios de Botucatu e São Manuel, SP. Irriga. 2009;14(1):1-11, doi: 10.15809/irriga.2009v14n1p1-11

16. Prado RC. Resenha climatológica (1971 a 2006). São Manuel-SP. 2013. Disponível em:< http://www.fca.unesp.br/\#!/instituicao/departamentos/solos-recursos-ambientais/sra/estacaometeorologica/resenha-climatologica/>.

17. Empresa Brasileira de Pesquisa Agropecuária - EMBRAPA. Sistema brasileiro de classificação dos solos. Brasília: EMBRAPA, 2006, 306 p. 
18. Silva JBC, Lopes CA, Magalhães J. Batata-doce (Ipomoea batatas). Embrapa Hortaliças - Sistemas de Produção, $6 . \quad$ Versão $\quad$ Eletrônica. $2008 . \quad$ Disponível http://sistemasdeproducao.cnptia.embrapa.br/FontesHTML/Batata-doce/Batatadoce_Ipomoea_batatas/introducao.html.

19. Nelson, N. A photometric adaptation of Somogyi method for the determination of glucose. J Biol Chem. 1944; 153:375-380.

20. Ferreira DF. SISVAR - Sistema de Análise de Variância. Versão 5. 3. Lavras-MG: UFLA, 2010.

21. Rós AB, Narita N. Produção de mudas de batata-doce a partir de poucas plantas matrizes. Rev Bras Ciênc Agr. 2011(c);6(1):85-89, doi: 10.5039/agraria.v6ila965

22. Gomes EM, Krinski D. Propagação vegetativa de Piper umbellatum L. (Piperaceae) em função de substratos e comprimentos de estacas. Sci Agraria. 2016;17(3):31-37, doi: 10.5380/rsa.v17i3.49695

23. Ehlert PAD, Luz JMQ, Innecco, R. Propagação vegetativa da alfavaca-cravo utilizando diferentes tipos de estacas e substratos. Hortic Bras. 2004;22(1):10-13, doi: 10.1590/S0102-05362004000100002

24. Rós AB, Hirata ACS, Narita N, Oliveira SR. Influência de nitrogênio e posição da mini-estaca no ramo na produção de mudas de batata-doce Uruguaiana. II Simpósio de Propagação de Plantas e Produção de Mudas, 2018; Águas de Lindóia. Agência Paulista de Tecnologia dos Agronegócios, 2018. Disponível em: 〈http://www.simpmudas.com.br/anais/busca-no-cd.html>.

25. Rós AB, Fernandes AM, Montes SMN, Leonel M, Franco CML. Batata-doce. In: Leonel M, Fernandes AM, Franco CML, coord. Culturas amiláceas: batata-doce, inhame, mandioca e mandioquinha-salsa; Botucatu: CERAT/UNESP; 2015. p. 15-120.

26. Azevedo SM, Freitas JA, Maluf WR, Silveira MA. Desempenho de clones e métodos de plantio de batata-doce. Acta Sci Agro. 2000;22(4):901-905.

27. Islam, AFMS, Kubota C, Takagaki M, Kozai T. Effects of ages of plug transplants and planting depths on the growth and yield of sweet potato. Sci Hortic. 2006;108(2):121-126, doi: 10.1016/j.scienta.2006.01.011

28. He D, Lok YH, Chun C, Kozai, T. Yield and growth of sweet potato using plug transplants as affected by cell volume of plug tray and type of cutting. In: Kubota C, Chun C, editores. Transplant Production in the 21st Century; Netherlands: Kluwer Academic Publishers; 2000. p. 154-159.

29. Wang H. The breeding of sweet potato for human consumption. In: Villareal RL, Grigs TD, editores. Sweet potato. I International Symposium; 1981 Mar 23-27; Taiwan. Asian Vegetable Research and Development Center Publication Tainan, Taiwan, 1982. p. 297-311.

30. Echer FR, Dominato JC, Creste JE. Absorção de nutrientes e distribuição da massa fresca e seca entre órgãos de batata-doce. Hortic Bras. 2009;27(2):176-182, doi: 10.1590/S0102-05362009000200010

31. Leonel M, Jackey S, Cereda MP. Processamento industrial de fécula de mandioca e batata doce - um estudo de caso. Ciênc Tecnol Aliment. 1998;18(3):343-345, doi: 10.1590/S0101-20611998000300016

32. Oliveira AP, Oliveira MRT, Barbosa JA, da Silva GG, Nogueira DH, de Moura MF, Braz MSS. Rendimento e qualidade de raízes de batata-doce adubada com níveis de uréia. Hortic Bras. 2005;23(4):925-928, doi: 10.1590/S0102-05362005000400012

33. Uda CF, Putarov NB, Bavelloni PL, Marcolino VA. Extração e caracterização do grão de amido de batata, batata-doce e mandioca. Rev Unig. 2008;17(1). Disponível em: <http://revista.uninga.br/index.php/uninga/article/view/692>.

34. Corrêa CV, Gouveia MAS, Evangelista RM, Cardoso AII. Qualidade de raízes de batata-doce em função das cultivares e do armazenamento. Rev Raíz Am Trop. 2016;12(1):26-35, doi: 10.17766/1808981X.2016v12n1p26-35

35. Nóbrega DS, Peixoto JR, Vilela MS, Nóbrega AKS, Santos EC, Costa AP, Carmona R. Yield and soil insect resistance in sweet potato clones. Biosc J. 2019;35(6):1773-1779, doi:10.14393/BJ-v35n6a201942452 